\title{
Role of asymmetric dimethylarginine in cardiovascular disease and diabetes
}

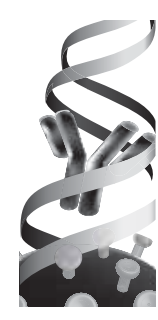

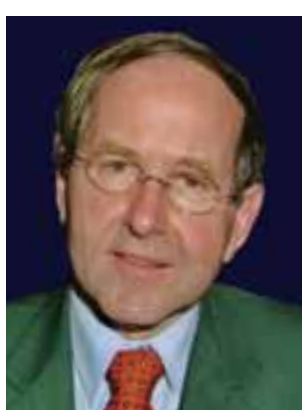

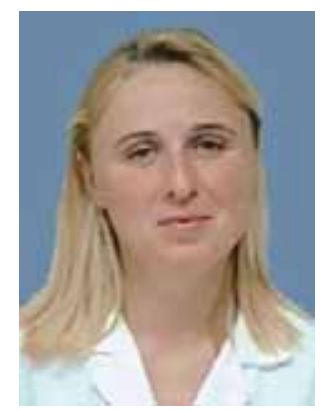

Guntram Schernthaner ${ }^{1}$ \& Katarzyna Krzyzanowska ${ }^{2 \dagger}$

${ }^{\dagger}$ Author for correspondence 1D epartment of Internal M edicinel, Rudolfstiftung H ospital, Juchgasse 25, 1030, Vienna, Austria Tel.: +43171 165 2101; Fax: +43 171165 2109; E-mail: guntram@ schernthaner.eu ${ }^{2} D$ epartment of Internal M edicinel, Rudolfstiftung H ospital, Juchgasse 25 , 1030, Vienna, Austria Tel.: +43171 165 2107; Fax: +43 171165 2109; E-mail: katarzyna. krzyzanowska@wienkav.at

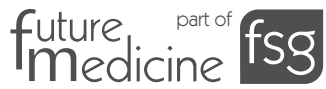

\author{
‘...ADMA is a n emerging \\ independent risk ma rker for future \\ cardiova scular events.'
}

The endogenous competitive nitric oxide (N O) synthase inhibitor asymmetric dimethylarginine

(ADM A) is a naturally occurring amino acid [1]. It is produced by methylation of protein-bound L-arginine, which is catalyzed by protein arginine methyltransferases [2]. It is partly eliminated from the organism by renal filtration. In healthy individuals, approximately $10 \%$ of this methylated arginine is excreted via this mechanism. The predominant mode of elimination of ADMA occurs via enzymatic degradation by dimethylarginine dimethylaminohydrolase (DDAH) to citrulline and dimethylamine [3].

\section{ADMA \& cardiovascular disease}

Asymmetric dimethylarginine causes endothelial dysfunction in forearm resistance arteries [4]. It increases the systemic vascular resistance and arterial blood pressure and decreases cardiac output [5]. 0 wing to its biological actions and the considerable high concentrations found in patients with renal insufficiency, the relationship between ADMA and cardiovascular complications was first studied in these high-risk patients. In a prospective study, Zoccali et al. found a significant association between circulating AD M A and future cardiovascular events and mortality [6]. Other studies observed elevated ADMA in tions can reduce cardiovascular risk in humans. patients with normal or slightly impaired renal A specific pharmacological treatment to reduce function and an adverse cardiovascular risk pro- ADMA is not yet available. However, it was file, including patients with peripheral arterial demonstrated that other measures to reduce carocclusive disease [7], hypertension [8], hyper- diovascular risk, including endurance training in lipidemia [9], insulin resistance [10], Type 2 diabe patients with Type 1 diabetes [27] and in patients tes mellitus [11], Type 1 diabetes mellitus [12], with elevated cardiovascular risk [28], or weight patients with diabetic nephropathy [13,14], loss in morbidly obese patients [29], can decrease patients with hypopituitarism [15] or women with circulating ADMA concentrations. In vitro previous gestational diabetes [16]. Several studies experiments indicate that some drugs (e.g., pravhave reported a predictive value of ADM A for astatin, telmisartan or pioglitazone) can increase cardiovascular events. The occurrence of cardio- the activity or the production of the enzyme vascular end points in high-risk patients has been DDAH and thereby reduce AD M A [30-32]. Clinfound to be directly and independently associ- ical studies also report that treatment with metated with elevated ADMA concentrations in formin, ACE inhibitors, angiotensin receptor 
blockers or $\alpha$-lipoic acid can lower circulating AD M A concentrations [33-39]. The literature on the effect of statins and glitazones on ADM A is controversial [40-46]. While one trial reported an AD M A reduction during treatment with rosiglitazone, this was not observed in a different cohort $[10,47]$. H owever, it remains speculative whether modulation of ADMA by these treatments will also directly impact cardiovascular risk.

'There are also data that demonstrated that insulin resistance is rela ted to eleva ted concentrations of ADMA.'

\begin{abstract}
ADMA \& diabetes
Patients with diabetes have an adverse cardiovascular risk profile. Elevated AD M A concentrations have been described in patients with Type 2 and Type 1 diabetes [11,12]. Hyperglycemia per se may increase AD M A concentrations. O ne in vitro study demonstrated that elevated glucose levels are capable of inhibiting DDAH activity in cultured endothelial cells [40]. Clinical investigations in patients also indicate that ADM A is directly related to blood glucose levels [11,48]. As demonstrated in a recent study, strict glycemic control may exert anti-atherogenic effects by reducing ADMA levels in patients with Type 2 diabetes [49]. There are also data that demonstrated that insulin resistance is related to elevated concentrations of AD M A [10]. Recent evidence suggests that elevated ADM A concentrations are associated with glycemic control in different patient populations, which fits with the assumption that ADMA may serve as risk predictor for cardiovascular events [50,51].
\end{abstract}

Besides associations between AD M A and metabolic control, AD M A might also play an important role for the development of diabetic complications. AD M A is elevated in patients with Type 1 and Type 2 diabetes and diabetic nephropathy with micro- and macroalbuminuria [12,14]. ADM A is related to the progression of renal disease and might therefore have potentially adverse effects in patients with diabetic nephropathy $[52,53]$. Furthermore, elevated ADMA levels have been described in Type 2 diabetic patients with retinopathy [54]. Therefore, it is tempting to speculate that ADM A might act as a pathophysiologically relevant factor for diabetes-associated complications. N evertheless, hyperglycemia remains a major cause for both increased AD M A and the development of diabetic complications, which makes the interpretation of the data more complex.

In conclusion, ADMA is an emerging independent risk marker for future cardiovascular events. The clinical acceptance of this parameter will depend on the availability of a therapy to directly decrease ADMA, which could confirm the role of AD M A as a causal risk factor. Further studies are warranted in patients with diabetes, especially regarding the possible effects of AD M A on diabetes-associated complications.

\section{Financial \& competing interests disclosure}

Theauthorshaveno relevant affiliationsor financial involve ment with any organization or entity with a financial interest in or financial conflict with the subject matter or materials discussed in the manuscript. This includes employment, consultancies, honoraria, stock ownership or options, expert testimony, grants or patents received or pending, royalties

$\mathrm{N}$ o writing assistance was utilized in the production of this manuscript.
Bibliography

1. Vallance P, Leone A, Calver A, Collier J, $M$ oncada S: Accumulation of an endogenous inhibitor of nitric oxide synthesis in chronic renal failure. Lancet 339(8793), 572-575 (1992).

2. $M$ cBride $A E$, Silver PA: State of the arg: protein methylation at arginine comes of age. Cell 106(1), 5-8 (2001).

3. O gawa T, Kimoto M, Sasaoka K: Purification and properties of a new enzyme, N G,N G -dimethylarginine dimethylaminohydrolase, from rat kidney. J. Biol. Chem. 264(17), 10205-10209 (1989).

4. Calver A, Collier J, Leone A, M oncada S, Vallance $P$ : Effect of local intra-arterial asymmetric dimethylarginine (AD M A) on the forearm arteriolar bed of healthy volunteers. J. H um. H ypertens. 7(2), 193-194 (1993).

5. Achan $\mathrm{V}$, Broadhead $M, M$ alaki $M$ et al.: Asymmetric dimethylarginine causes hypertension and cardiac dysfunction in humans and is actively metabolized by dimethylarginine dimethylaminohydrolase. Arterioscler. Thromb. Vasc. Biol. 23(8), 1455-1459 (2003).

6. Zoccali C, Bode-Böger S, M allamaci $F$ et al.: Plasma concentration of asymmetrical dimethylarginine and mortality in patients with end-stage renal disease: a prospective study. Lancet 358(9299), 2113-2117 (2001).

7. Böger RH, Bode-Böger SM, Thiele W, Junker W, Alexander K, Frölich JC: Biochemical evidence for impaired nitric oxide synthesis in patients with peripheral arterial occlusive disease. Circulation 95(8), 2068-2074 (1997).

8. Surdacki A, N owicki M, Sandmann J et al.: Reduced urinary excretion of nitric oxide metabolites and increased plasma levels of asymmetric dimethylarginine in men with essential hypertension. J. Cardiovasc. Pharmacol. 33(4), 652-658 (1999).

9. Böger $\mathrm{RH}$, Bode-Böger $S M$, Szuba $A$ et al.: Asymmetric dimethylarginine (AD M A): a novel risk factor for endothelial dysfunction: its role in hypercholesterolemia. Circulation 98(18), 1842-1847 (1998).

10. Stühlinger M C, Abbasi F, Chu JW et al.: Relationship between insulin resistance and an endogenous nitric oxide synthase inhibitor. JAM A 287(11), 1420-1426 (2002). 


\section{Asymmetric dimethylarginine in cardiovascular disease \& diabetes - ED IT O RIAL}

11. Abbasi F, Asagmi T, C ooke JP et al.: Plasma concentrations of asymmetric dimethylarginine are increased in patients with Type 2 diabetes mellitus. Am. J. Cardiol. 88(10), 1201-1203 (2001).

12. Tarnow $L, H$ ovind $P$, Teerlink $T$, Stehouwer CD, Parving $\mathrm{H} \mathrm{H}$ : Elevated plasma asymmetric dimethylarginine as a marker of cardiovascular morbidity in early diabetic nephropathy in Type 1 diabetes. D iabetes C are 27(3), 765-769 (2004).

13. Krzyzanowska $K$, M ittermayer $F$, Krugluger $W$ et al.: Asymmetric dimethylarginine is associated with macrovascular disease and total homocysteine in patients with Type 2 diabetes. Atherosclerosis 189(1), 236-240 (2006).

14. Krzyzanowska K, M ittermayer F, Shnawa N et al.: Asymmetrical dimethylarginine is related to renal function, chronic inflammation and macroangiopathy in patients with Type 2 diabetes and albuminuria. D iabet. M ed. 24(1), 81-86 (2007).

15. Krzyzanowska K, M ittermayer $F$, Schnack C, H ofer M, Wolzt M, Schernthaner G: Circulating AD M A concentrations are elevated in hypopituitary adults with and without growth hormone deficiency. Eur. J. Clin. Invest. 35(3), 208-213 (2005).

16. $M$ ittermayer $F, M$ ayer $B X, M$ eyer $A$ et al.: Circulating concentrations of asymmetrical dimethyl-L-arginine are increased in women with previous gestational diabetes. Diabetologia 45(10), 1372-1378 (2002).

17. Schnabel R, Blankenberg $S$, Lubos $E$ et al.: Asymmetric dimethylarginine and the risk of cardiovascular events and death in patients with coronary artery disease: results from the AtheroG ene Study. Circ. Res. 97(5), e53-e59 (2005).

18. M ittermayer $F, K$ rzyzanowska $K$, Exner $M$ et al.: Asymmetric dimethylarginine predicts major adverse cardiovascular events in patients with advanced peripheral artery disease. Arterioscler. Thromb. Vasc. Biol. 26(11), 2536-2540 (2006).

19. Krzyzanowska $K, M$ ittermayer $F$, Wolzt $M$, Schernthaner G: Asymmetric dimethylarginine predicts cardiovascular events in patients with Type 2 diabetes. Diabetes Care 30(7), 1834- 1839 (2007).

20. Lajer $M$, Tarnow $L$, Jorsal $A$, Teerlink T, Parving H H , Rossing P: Plasma concentration of asymmetric dimethylarginine (AD M A) predicts cardiovascular morbidity and mortality in Type 1 diabetic patients with diabetic nephropathy. D iabetes Care 31(4), 747-752 (2008).

21. Dückelmann C, M ittermayer $F, H$ aider D G, Altenberger $\mathrm{J}$, Eichinger $\mathrm{J}$, Wolzt $\mathrm{M}$ : Asymmetric dimethylarginine enhances cardiovascular risk prediction in patients with chronic heart failure. Arterioscler. Thromb. Vasc. Biol. 27(9), 2037-2042 (2007).

22. Skoro-Sajer $N$, M ittermayer $F$, Panzenboeck A et al.: Asymmetric dimethylarginine is increased in chronic thromboembolic pulmonary hypertension. Am. J. Respir. Crit. Care M ed. 176(11), 1154-1160 (2007).

23. Suda O, Tsutsui M, M orishita T et al.: Asymmetric dimethylarginine produces vascular lesions in endothelial nitric oxide synthase-deficient mice: involvement of renin-angiotensin system and oxidative stress. Arterioscler. Thromb. Vasc. Biol. 24(9), 1682-1688 (2004).

24. Tanaka M, Sydow K, G unawan F et al.: Dimethylarginine dimethylaminohydrolase overexpression suppresses graft coronary artery disease. Circulation 112(11), 1549-1556 (2005).

25. M atsumoto $Y, U$ eda $S$, Yamagishi $S$ et al.: Dimethylarginine dimethylaminohydrolase prevents progression of renal dysfunction by inhibiting loss of peritubular capillaries and tubulointerstitial fibrosis in a rat model of chronic kidney disease. J. Am. Soc. N ephrol. 18(5), 1525-1533 (2007).

26. Konishi H, Sydow K, CookeJP: Dimethylarginine dimethylaminohydrolase promotes endothelial repair after vascular injury. J. Am. Coll. Cardiol. 49(10), 1099-1105 (2007).

27. M ittermayer F, Pleiner J, K rzyzanowska K, W iesinger GF, Francesconi $M$, Wolzt $M$ : Regular physical exercise normalizes elevated asymmetrical dimethylarginine concentrations in patients with Type 1 diabetes mellitus. Wien. Klin. Wochenschr. 117(23-24), 816-820 (2005)

28. Richter $B, N$ iessner $A$, Penka $M$ et al.: Endurance training reduces circulating asymmetric dimethylarginine and myeloperoxidase levels in persons at risk of coronary events. Thromb. H aemost. 94(6), 1306-1311 (2005).

29. K rzyzanowska K, M ittermayer F, Kopp H P, Wolzt M, Schernthaner G: Weight loss reduces circulating asymmetrical dimethylarginine concentrations in morbidly obese women. J. Clin. Endocrinol. M etab. 89(12), 6277-6281 (2004).
30. Yin Q F, Xiong Y: Pravastatin restores DDAH activity and endotheliumdependent relaxation of rat aorta after exposure to glycated protein. J. Cardiovasc. Pharmacol. 45(6), 525-532 (2005).

31. Scalera F, M artens-Lobenhoffer J, Bukowska A, Lendeckel U, Tager M , Bode-Boger SM : Effect of telmisartan on nitric oxide: asymmetrical dimethylarginine system: role of angiotensin II type 1 receptor- $\gamma$ and peroxisome proliferatoractivated receptor- $\gamma$ signaling during endothelial aging. $\mathrm{H}$ ypertension 51(3), 696-703 (2008).

32. Wakino $\mathrm{S}, \mathrm{H}$ ayashi $\mathrm{K}$, Tatematsu $\mathrm{S}$ et al.: Pioglitazone lowers systemic asymmetric dimethylarginine by inducing dimethylarginine dimethylaminohydrolase in rats. H ypertens. Res. 28(3), 255-262 (2005).

33. Chang JW, LeeEK, Kim TH et al.: Effects of $\alpha$-lipoic acid on the plasma levels of asymmetric dimethylarginine in diabetic end-stage renal disease patients on hemodialysis: a pilot study. Am. J. N ephrol. 27(1), 70-74 (2007).

34. H eutling D, Schulz H, N ickel I et al.: Asymmetrical dimethylarginine, inflammatory and metabolic parameters in women with polycystic ovary syndrome before and after metformin treatment. J. Clin. Endocrinol. M etab. 93(1), 82-90 (2008).

35. Asagami $T$, Abbasi $F$, Stuelinger $M$ et al.: $M$ etformin treatment lowers asymmetric dimethylarginine concentrations in patients with Type 2 diabetes. M etabolism 51(7), 843-846 (2002).

36. Chen JW, H su N W, Wu TC, Lin SJ, Chang M S: Long-term angiotensinconverting enzyme inhibition reduces plasma asymmetric dimethylarginine and improves endothelial nitric oxide bioavailability and coronary microvascular function in patients with syndrome $X$. Am. J. Cardiol. 90(9), 974-982 (2002).

37. N apoli C, Sica $V$, de N igris $F$ et al.: Sulfhydryl angiotensin-converting enzyme inhibition induces sustained reduction of systemic oxidative stress and improves the nitric oxide pathway in patients with essential hypertension. Am. H eart J. 148(1), e5 (2004).

38. Ito $A$, Egashira $K, N$ arishige $T$, M uramatsu K, Takeshita A: Renin-angiotensin system is involved in the mechanism of increased serum asymmetric dimethylarginine in essential hypertension. J pn Circ. J. 65(9), 775-778 (2001). 
39. Kawata $T$, D aimon $M, H$ asegawa $R$ et al.: Effect of angiotensin-converting enzyme inhibitor on serum asymmetric dimethylarginine and coronary circulation in patients with Type 2 diabetes mellitus. Int. J. Cardiol. (2007) (Epub ahead of print).

40. Lin KY, Ito A, Asagami T et al.: Impaired nitric oxide synthase pathway in diabetes mellitus: role of asymmetric dimethylarginine and dimethylarginine dimethylaminohydrolase. Circulation 106(8), 987-992 (2002).

41. Paiva H, Laakso J, Lehtimaki T, Isomustajarvi M , Ruokonen I, Laaksonen R: Effect of high-dose statin treatment on plasma concentrations of endogenous nitric oxide synthase inhibitors. J. Cardiovasc. Pharmacol. 41(2), 219-222 (2003).

42. Valkonen VP, Laakso J, Paiva H et al.: Asymmetrical dimethylarginine (ADM A) and risk of acute coronary events. D oes statin treatment influence plasma AD M A levels? Atheroscler. Suppl. 4(4), 19-22 (2003).

43. Shinohara K, Shoji T, Kimoto E et al.: Effect of atorvastatin on regional arterial stiffness in patients with Type 2 diabetes mellitus. J. Atheroscler. Thromb.. 12(4), 205-210 (2005).

44. Eid H M, Eritsland J, Larsen J, Arnesen H, Seljeflot I: Increased levels of asymmetric dimethylarginine in populations at risk for atherosclerotic disease. Effects of pravastatin. Atherosclerosis 166(2), 279-284 (2003).
45. Pereira EC, Bertolami MC, Faludi AA, Salem M, Bersch D, Abdalla D S: Effects of simvastatin and $L$-arginine on vasodilation, nitric oxide metabolites and endogenous N OS inhibitors in hypercholesterolemic subjects. Free Radic. Res. 37(5), 529-536 (2003).

46. Lu TM, Ding YA, Leu HB, Yin WH, Sheu WH , Chu KM : Effect of rosuvastatin on plasma levels of asymmetric dimethylarginine in patients with hypercholesterolemia. Am. J. Cardiol. 94(2), 157-161 (2004).

47. Kelly AS, Thelen AM, Kaiser D R, Gonzalez-Campoy JM, Bank AJ: Rosiglitazone improves endothelial function and inflammation but not asymmetric dimethylarginine or oxidative stress in patients with Type 2 diabetes mellitus. Vasc. M ed. 12(4), 311-318 (2007)

48. Worthley M I, H olmes AS, W illoughby SR et al.: The deleterious effects of hyperglycemia on platelet function in diabetic patients with acute coronary syndromes mediation by superoxide production, resolution with intensiveinsulin administration. J. Am. Coll. Cardiol. 49(3), 304-310 (2007).

49. Yasuda S, M iyazaki S, Kanda M et al.: Intensive treatment of risk factors in patients with Type 2 diabetes mellitus is associated with improvement of endothelial function coupled with a reduction in the levels of plasma asymmetric dimethylarginine and endogenous inhibitor of nitric oxide synthase. Eur. H eart J. 27(10), 1159-1165 (2006).

50. Anderson JL, Carlquist JF, Roberts W L et al.: Asymmetric dimethylarginine, cortisol/cortisone ratio, and C-peptide: markers for diabetes and cardiovascular risk? Am. H eart J. 153(1), 67-73 (2007).

51. M ittermayer $F$, Kautzky-W iller A, W inzer $C$ et al.: Elevated concentrations of asymmetric dimethylarginine are associated with deterioration of glucose tolerance in women with previous gestational diabetes mellitus. J. Intern. M ed. 261(4), 392-398 (2007).

52. Ravani P, Tripepi G, M alberti F, Testa S, M allamaci F, Zoccali C: Asymmetrical dimethylarginine predicts progression to dialysis and death in patients with chronic kidney disease: a competing risks modeling approach. J. Am. Soc. N ephrol. 16(8), 2449-2455 (2005).

53. U eda S, Yamagishi S, M atsumoto $Y$, Fukami K, O kuda S: Asymmetric dimethylarginine (ADM A) is a novel emerging risk factor for cardiovascular disease and the development of renal injury in chronic kidney disease. Clin. Exp. N ephrol. 11(2), 115-121 (2007).

54. M alecki M T, Undas A, Cyganek $K$ et al.: Plasma asymmetric dimethylarginine (AD M A) is associated with retinopathy in Type 2 diabetes. Diabetes Care 30(11), 2899-2901 (2007). 